\title{
Seres do Subterrâneo: Os Invisíveis do Mundo Moderno
}

\section{Beings from Underground: The Invisible World Modern}

\author{
Felipe Borges Amaral ${ }^{1}$, Ketlle Duarte Paes ${ }^{1}$ \\ ${ }^{1}$ Universidade Federal do Rio Grande do Sul, UFRGS, Brasil \\ Correspondência: Ketlle Duarte Paes. Endereço: Endereço: Av. Paulo Gama, 110, Farroupilha, Porto Alegre, RS, \\ CEP 90040060. Tel.: 5551 3308-6000. E-mail: ketllep@yahoo.com.br
}

Recebido: 06 de julho de 2016 Aceito: 30 de junho de 2017 Publicado: 31 de maio de 2017

DOI: http://dx.doi.org/10.21714/1679-18272016v14n1.p367-380

\begin{abstract}
Resumo
Este ensaio faz parte de um conjunto de estudos que discute o uso de abordagens influenciadas pelo pensamento único, fundamentadas no paradigma funcionalista, como lentes para compreender práticas sociais atravessadas por múltiplas racionalidades. Neste ensaio, partimos dessa preocupação e buscamos marcos teóricos nãoortodoxos em estudos organizacionais. Para tanto, mobilizaremos as abordagens teóricas propostas por Boaventura Santos e Paulo Freire com o objetivo de lançar luz às ausências sociais produzidas ativamente pela razão indolente no campo disciplinar dos estudos organizacionais. Com o seu formato ensaístico, o leitor não deve esperar conclusões sólidas, comprovações claras ou certezas tranquilizadoras. A partir daí se pode inferir que as abordagens aqui propostas nos ajudam nos atos de denúncia das ausências artificialmente produzidas, bem como nos atos anúncios de outras sociabilidades, abrindo espaço assim, para o reconhecimento do novo, do que está em construção, e do que ainda não é.
\end{abstract}

Palavras-chave: sociologia das ausências; sociologia das emergências, pedagogia do oprimido; estudos organizacionais.

\begin{abstract}
This essay is part of a set of studies that discusses the use of approaches influenced by one thought, based on the functionalist paradigm as a lens for understanding social practices traversed by multiple rationales. In this essay we leave this concern and seek unorthodox in organizational studies theoretical frameworks. To this end, mobilize the proposals by Boaventura Santos and Paulo Freire aiming to shed light on social absences actively produced by the lazy reason disciplinary field of organizational studies theoretical approaches. With his essay format, the reader should not expect robust conclusions, clear evidence or reassuring certainties. From this one can infer that the approaches proposed here help us in acts of denunciation of artificially produced absences as well as the acts of other ads sociability, thus making room for the recognition of the new, which is under construction, and that still is not.
\end{abstract}

Keywords: sociology of absences; sociology of emergences, pedagogy of the oppressed; organizational studies.

Esta obra está licenciada sob uma Licença Creative Commons Attribution 3.0.

\section{Introdução}

Em Josefina, a Cantora ou O Povo dos Camundongos, Franz Kafka (1998) narra a história de uma comunidade de ratos, onde Josefina, ao exercitar seu assobiar, ao emitir seus singelos ruídos, consegue deter a audiência de toda sua comunidade. A voz de Josefina não é especial. Ela não é especial. Josefina nada representa a não ser a homogeneidade daquele povo, enquanto indivíduos singulares. São eles, pois, iguais em sua singularidade. Josefina luta para que seja dispensada do trabalho diário, em razão do seu ofício de cantora. Contudo, não obtém êxito e desaparece narcisicamente, na expectativa de ser valorizada por sua ausência. Erro de cálculo. O povo segue tranquilo, sem desilusão aparente, "uma massa que encontra em si mesma o equilíbrio", certos de que não perderão muito (KAFKA, 1998. p. 59).

O pensamento único/universalizante produz ausências e homogeneizações artificiais (SANTOS, 2002) a ponto de a singularidade de um sujeito desaparecer, como é o caso de Josefina, a cantora do conto de Kafka. Nesse sentido, Boaventura de Sousa Santos (2002), observa que vivemos, no presente, um tempo de ambiguidade e de transição, difícil de entender e de percorrer. Diante dessa constatação, o autor nos convida a refletir sobre novas possibilidades de sociabilidade produzidas a partir de experiências alternativas à razão indolente que emergem dos subterrâneos do pensamento hegemônico. 
$\mathrm{O}$ autor nos leva a questionar a racionalidade dominante que produz ativamente como não existentes as experiências sociais alternativas numa operação de expansão do presente e de contração do futuro, ocultando todas as temporalidades existentes e possíveis de existir. Os reflexos da razão indolente se fazem sentir nas ciências sociais em geral e em suas disciplinas relativamente autônomas como, por exemplo, as ciências das organizações, um campo de estudos importante no âmbito desse ensaio.

Assim, lançando luz aos pontos mais recônditos do espaço social e, portanto, fazendo coro às reflexões de Boaventura de Souza Santos (ausência/emergência) bem como às de Paulo Freire (denúncia/anúncio) perguntamos: O que sabemos sobre Bradley Manning? Ou sobre Aaron Swartz? Quem foi Mohamed Bouazizi? Possivelmente muitos de nós não conheçamos estes nomes. Nada saibamos sobre o soldado americano que divulgou informações e vídeos sobre ataques a civis em Bagdá e ficou em confinamento solitário por mais de dois anos sem julgamento. E, o que sabemos sobre o jovem aficionado por tecnologia que salvou artigos científicos de uma importante base de dados paga para distribuí-los gratuitamente? Esse jovem foi processado criminalmente e, não suportando a pressão, suicidou-se recentemente. É de se pensar, por fim, que nos seja desconhecido, também, o suicídio por imolação do vendedor de frutas da Tunísia que protestava contra a apreensão de suas mercadorias.

O que estes personagens têm em comum, além do fato de que suas histórias de vida, e de morte em alguns casos, serem desconhecidas do grande público? Todos eles ousaram insurgir-se contra o modelo de dominação vigente. Todos eles são desconhecidos, inexistentes, ausentes para o grande público. São ausentes porque produzidos como tal (SANTOS, 2002). São ausentes porque suas posturas confrontadoras e contestadoras são descridibilizadas e inviabilizadas pela hegemonia da razão indolente. Nem a mídia hegemônica e nem o Estado os reconhece. Há um véu que inebria a todos e impede que se vejam os elementos que colocam em risco as estruturas estabelecidas.

O que propomos nas páginas a seguir é tratar das ausências produzidas (SANTOS, 2002), bem como dos anúncios de novas sociabilidades (FREIRE, 2011). Portanto, buscamos, com esse ensaio, refletir sobre a posição ocupada pelos Estudos Organizacionais na (re)produção das ausências, bem como sua participação nos atos de anúncio. A razão indolente produz como ausentes outras formas de organização que não aquelas produtivas, burocráticas e pautadas pelo econômico. Há, portanto, que se resgatar os saberes ocultados pela hegemonia, como bem observa Scherer-Warren (2012), para quem o intelectual tem a obrigação de fazer uma análise crítica sobre o lugar de sua fala. Isso porque, para a autora, há uma memória oficial hegemônica e uma memória coletiva dos oprimidos, ou seja, há uma memória intelectual hegemônica e uma memória de saberes historicamente subalternos.

O campo dos estudos organizacionais, tradicionalmente, o desenvolvimento teórico vem sendo traçado no contexto das correntes de pensamento ligadas ao positivismo e ao estruturo-funcionalismo, restringindo o pensar sobre as organizações a uma delimitação específica, qual seja as organizações pautadas pela busca da eficiência e da ordem (PARKER, 2002; PAULA, 2002; BOHM, 2006; MISOCZKY, 2010).

Essa organização produtiva, burocrática e com objetivos financeiros está consubstanciada na ideia de empresa (SOLÉ, 2004). O culto à empresa promove a difusão massiva do discurso gerencialista por diversas esferas da vida humana associada, engendrando o que Chanlat (2000) denominou de sociedade managerial. Neste tipo de sociedade, as empresas possuem um papel central na produção de discursos e princípios gerenciais, tais como eficiência, produtividade, desempenho, planejamento, etc. que invadem as mais variadas realidades sociais para além das organizações atuantes no mercado (CHANLAT, 2000).

De acordo com Bohm (2006), a noção hegemônica de organização está associada a regras formais, procedimentos técnicos, profissionalismo, burocracia e sujeitos racionais que podem ser alocados, medidos e controlados. Vista desta maneira, a organização se restringe à administração e à manutenção de um mundo hierárquico, padronizado e harmônico, sustentado pela ideologia da neutralidade da técnica, da ordem e do progresso. Bohm (2006) afirma, ainda, que o modelo tradicional de organização se caracteriza por uma noção de organização que possui estreita conexão com o gerencialismo e o capitalismo. Esta maneira racional e formal de significar a organização tem sido a ideologia predominante da teoria organizacional (BOHM, 2006; CLEGG, 1998; PARKER, 2002).

No entanto, nenhuma hegemonia consegue dar conta de toda a realidade social Misoczky et al (2010) afirmam que organizar não é sinônimo de organizar de modo burocrático ou de prática gerencial, sendo uma produção social de modos de cooperação contingente e em movimento. Os autores observam que uma das tarefas políticas mais importantes dos estudos críticos no campo disciplinar dos Estudos Organizacionais é a investigação dos processos de organização da resistência e das lutas sociais que tendem a ser ignoradas pelo discurso organizacional hegemônico. 
Na visão de Bohm (2006), a resistência à hegemonia da gestão pode ser encontrada em diversos espaços: pelo trabalhador no seu local de trabalho, pelas organizações sindicais, pelos movimentos sociais e pelas organizações da sociedade civil. Bohm (2006) e Parker (2002) acreditam que os movimentos sociais são importantes espaços de resistência à globalização, ao capitalismo e à forma organizacional dominante.

Misoczky (2010) defende que para se levar a cabo este desafio é preciso questionar a noção hegemônica de organização, associada à ideia de empresa e, para tanto, há de se deslocar as categorias de análise tradicionais nos estudos organizacionais como hierarquia, delegação, representação e individualismo, bem como reposicionar a reprodução da práxis burocratizada.

A autora sugere também que lancemos luz a algumas categorias e valores que vêm se tornando recorrentes na análise das organizações e apresentam-se com potencial contra-hegemônico, tais como a horizontalidade, a participação direta nas decisões, a construção coletiva da organização e de suas práticas, valores orientados para a vida, tolerância e solidariedade na relação com a alteridade (MISOCZKY, 2010).

Assim, a importância desse ensaio insere-se na perspectiva de uma contribuição teórica para as pesquisas que buscam desnaturalizar os fundamentos epistemológicos da área da administração (SERVA et al, 2010; CARVALHO e VIEIRA, 2007; PAES DE PAULA, 2008, 2012; MISOCZKY E FLORES, 2009, BOEIRA et al, 2012) que veem no management a única e melhor forma de organizar (PARKER, 2002) fundada nos pressupostos de eficiência e do cálculo utilitário de consequência. Isso porque, conforme apontam Serva et al (2010) apesar da necessidade urgente de desenvolver teorias que tentem explicar as práticas organizacionais de uma forma mais complexa, a grande maioria das pesquisas desenvolvidas na área ainda apresenta métodos tradicionais de orientação positivista e funcionalista.

Assim, esse estudo pretende contribuir para a área de Estudos Organizacionais como mais uma opção não ortodoxa de análise para os fenômenos organizacionais, lançando um novo olhar para realidades ininteligíveis pela razão dominante, produzidas ativamente como não existentes, mas que se constituem em práticas sociais dotadas de uma racionalidade própria, com temporalidade própria e existentes em um espaço social mais amplo.

A herança cartesiano-kantiana nos transmite a noção de sujeito-racional, dotado do predicado da razão sob cuja égide faz escolhas conscientes. Tal herança ainda nos transmite os valores metafísicos de uma sociedade reconciliada e de um discurso teleológico de pleno conhecimento sobre a verdade das coisas.

Neste ponto, as teorias organizacionais partidárias da pretensão de compreensão plena do mundo, de uma banda, limitando-se a uma ideia de homem econômico, e de outra, incorporando o conceito de homem complexo. Em ambos os casos, contudo, o que se verifica é que a base que sustenta essas ideias de homem é aquela advinda da noção de sujeito na modernidade, o sujeito racional, o cálculo de meios e fins. Restam ausentes as diferentes formas de operar o pensamento e a escrita.

Este texto é, portanto, um exercício de reflexão filosófica que, ao mesmo tempo em que identifica, circunda e delimita o objeto, afasta-se dele, deixa-o enevoar-se, seguindo na direção do sujeito. Este espaço de imprecisão no qual se dá um movimento de aproximação e afastamento acompanha desconstrução de centros e origens inabaláveis proposta por Jacques Derrida, permitindo que se configure, em seu lugar, a contaminação pelas margens.

Uma contaminação que origina movimentos impuros, permite a penetração marginal fragilizando noções tradicionais e estáveis da modernidade e se distanciando da metafísica da presença. É com Derrida, em seu Margens da Filosofia, que seguimos para pensar que a filosofia não basta sem a literatura. Para o autor há necessidade de lermos o texto filosófico contemplando a sua veia literária, superar os limites entre filosofia e literatura, pensar um gênero outro:

Uma tarefa então é prescrita: estudar o texto filosófico na sua estrutura formal, na sua organização retórica, na sua especificidade e diversidades de seus tipos textuais, nos seus modelos de exposição e produção - para além daquilo que outrora se chamava os gêneros - no espaço também das suas encenações e numa sintaxe que não seja apenas a articulação dos seus significados, das suas referências ao ser ou à verdade, mas a ordenação de seus processos e de tudo o que aí se investiu. Em suma, considerar também a filosofia como 'um gênero literário particular', extraindo da reserva de uma língua, arranjando, forçando ou desviando um conjunto de recursos trópicos mais antigos do que a filosofia (DERRIDA, 1991, p. 334-335).

Pensar os movimentos dos quais falamos sob a ótica de Paulo Freire e Boaventura de Sousa Santos, entrecruzar esta temática com a inserção da forma ensaística de redação nos Estudos Organizacionais, é fazer uma literatura menor. Trata-se da operação que Kafka executou com o alemão. A negação da escrita aos judeus de Praga faz da sua literatura algo de impossível. (DELEUZE; GUATTARI, 2014) Como ensaio, este trabalho "não almeja uma construção fechada, dedutiva ou indutiva. Ele se revolta sobretudo contra a doutrina, arraigada desde Platão, 
segundo a qual o mutável e o efêmero não seriam dignos da filosofia.” (ADORNO, 2003, p. 25) É assim que, em sua fragilidade, denuncia a própria não identidade e o "pensamento se desembaraça da ideia tradicional de verdade" (ADORNO, 2003, p. 27).

Não há aqui proposições encadeadas em um sentido estritamente lógico, tampouco uma restrição interna paradigmática que nos coloque em uma imediata filiação teórica. O que há aqui é experimentação de pensamento em forma de escrita. Não há postulados a comprovar, não há afirmações de absoluta certeza e plena veracidade. Não estamos certos, nem mesmo, de que sobre algo se possam fazer tais afirmações. Como ratos que correm sob nossos pés e emergem aqui ou lá - seja com guinchos ou assovios - também nos erigimos certas vezes para apontar o não-visto, o não-sabido, o ausente.

Nesse sentido, seguimos aqui as intuições bem fundamentadas do texto $\mathrm{O}$ que é um ensaio teórico? (MENEGHETTI, 2011, p. 02) e corroboramos a ideia segundo a qual "o espírito de um ensaio teórico" revela a "relação permanente entre o sujeito e objeto, um vir-a-ser constituído pela interação da subjetividade com a objetividade dos envolvidos. Do mesmo modo nos serve de inspiração os dizeres do autor sobre essa modalidade de escrita:

Este ensaio deve ser lido por sujeitos com espíritos livres de preconceitos, sem estarem dominados pelo formalismo da ciência. Aqui o leitor não encontrará a disposição formal de um estudo que segue a divisão e a lógica estabelecida pelas metodologias científicas tradicionais. No lugar do objetivo geral, dos objetivos específicos, da justificativa, da fundamentação teórica, da metodologia que define os critérios de coleta e análise de dados e da conclusão, no ensaio a orientação é dada não pela busca das respostas e afirmações verdadeiras, mas pelas perguntas que orientam os sujeitos para as reflexões mais profundas (MENEGHETTI, 2011, p. 02).

Segundo o autor, o ensaio, diferente da lógica da ciência não é instrumento da identidade entre sujeito e objeto, mas um meio para apreender a realidade e uma ruptura com o princípio da identidade e unicidade que embasa a filosofia tradicional e consequentemente as ciências sociais. Assim, entendemos que este seja, adequadamente, o papel do ensaio. "O ensaísta abandona suas próprias e orgulhosas esperanças [...], ele nada tem a oferecer além de explicações de poemas dos outros ou, na melhor das hipóteses, das suas próprias ideias" (ADORNO, p 25). O ensaio deve mesmo ser tomado no sentido de seu equivalente em alemão Versuch - experiência - buscando colocar dilemas e evidenciar as falácias das "saídas pretensamente definitivas [... e] o fracasso das leituras teóricas lineares, com a intenção de levar os problemas 'a bom porto"” (BARRENTO, 2013, p. 35)

Apresentados os objetivos, e feitas as considerações sobre nossa forma de construção das ideias ora apresentadas, resgatamos o início do ensaio para recuperar e apresentar ao leitor os sujeitos por meio dos quais pretendemos refletir as ausências e os anúncios em organizações. Assim, Bradley Manning, como adiantamos, é um soldado americano que, lutando no Iraque contra as forças de Sadan Houssein, divulgou um vídeo em que um helicóptero dos Estados Unidos atira contra um ônibus lotado de civis. O militar foi preso e logo surgiram mais suspeitas de que o vazamento de documentos do exército norte-americano ao site da WikiLeaks fosse sua responsabilidade. Recentemente, foi julgado por parte dos crimes que lhe são imputados. Condenado, finalmente teve conhecimento da pena que lhe será aplicada. Após a sentença, Bradley Manning declarou-se transgênero, e pediu que a imprensa passe a lhe chamar Chelsea Manning.

A WikiLeaks é uma organização sueca, cujo principal expoente é o jornalista australiano Julian Assange. Durante o ano de 2010 a WikiLeaks fez uma série de denúncias envolvendo os Estados Unidos, entre elas, um vídeo em que um helicóptero dos Estados Unidos atira contra um ônibus lotado de civis e documentos contendo instruções para o tratamento de prisioneiros mantidos pelos norte-americanos em Guantánamo, Cuba.

Bradley Manning está preso. Julian Assange está preso. O primeiro permaneceu mais de dois anos em isolamento carcerário sem poder dirigir-se a um juiz, em condições "cruéis, desumanas e degradantes" (GREENWALD, 2010; TUTU, CORRIGAN-MAGUIRE, ESQUIVEL, 2012.). Julian Assange, após acusações de estupro na Suécia apresentou-se à polícia de Londres, onde vivia. Os Estados Unidos por sua vez, mantendo um favorável acordo de extradição com a Suécia, contam com a sua chegada ao país nórdico para processá-lo por espionagem e fraude.

Em torno de Bradley Manning organizou-se um movimento de apoio mundial. Milhões de pessoas nas mais diversas partes do globo manifestaram o seu apoio publicando na Internet fotos suas com um cartaz dizendo "I am Bradley Manning". Desmond Tutu, Mairead Corrigan-Maguire e Adolfo Pérez Esquivel, laureados com o Prêmio Nobel da Paz, publicaram, nos jornais The Nation e The Guardian uma matéria de denúncia e claro apoio ao soldado. Ao finalizarem, afirmam:

Se Bradley Manning divulgou os documentos que a promotoria afirma, devemos expressar-lhe nossa gratidão pelos seus esforços para a prestação de contas do governo, a democratização da informação e a paz (TUTU, CORRIGAN-MAGUIRE, ESQUIVEL, 2012). 
Mohamed Bouazizi, 24 anos, tunisino, não conseguiu encontrar um emprego formal. Para ajudar a família, passou a vender frutas e verduras, que foram apreendidas pela polícia por falta de licença. Tentou resolver o caso com o governo local e, não obtendo sucesso, ateou fogo sobre o próprio corpo (BYRNE, 2011; LEVS, 2011; ALARAB; HUNT, 2011).

$\mathrm{O}$ acontecimento descrito acima é tomado por analistas internacionais como deflagrador de uma série de revoltas ocorridas no país, que culminaram com a renúncia do então presidente Ben Ali, que estava há 23 anos no poder (LEVS, 2011; AL-ARAB; HUNT, 2011). Para Slavoj Žižek (2012) o impacto e a significação são ainda maiores.

[...] foi apenas um dos muitos atos semelhantes ocorridos no norte da África que, além do desespero individual simbolizaram o esgotamento psicológico de muitos povos em um mesmo momento. Houve uma sincronia cosmopolita febril e viral de uma sequência de rebeliões quase espontâneas surgidas na margem sul do Mediterrâneo e que logo se manifestaram na Espanha, com os Indignados da Puerta del Sol, em Portugal, com a Geração à Rasca, e na Grécia, com a ocupação da praça Syntagma (ŽIŽEK, 2012. p.8).

Em todos os países citados, e em tantos outros como o Brasil, a forma de ação foi semelhante, incluindo a ocupação de espaços públicos, a auto-organização dos movimentos por meio da comunicação através da Internet e articulações fora dos espaços institucionais tradicionais (ŽIŽEK, 2012).

Programador de computadores, desenvolvedor de muitas das tecnologias que utilizamos hoje na internet e fundador de sites importantes como o Watchdog, site para a criação de petições online, Aaron Swartz dizia:

Eu acredito que você deve sempre estar se questionando. Eu levo muito a sério essa atitude científica de que tudo o que você aprende é provisório, tudo é aberto ao questionamento e à refutação. $\mathrm{O}$ mesmo se aplica à sociedade. Eu cresci e através de um lento processo percebi que o discurso de que nada pode ser mudado e que as coisas são naturalmente como são é falso. Elas não são naturais. As coisas podem ser mudadas. E mais importante: há coisas que são erradas e devem ser mudadas. Depois que percebi isso, não havia como voltar atrás. Eu não poderia me enganar e dizer: "Ok, agora vou trabalhar para uma empresa". Depois que percebi que havia problemas fundamentais que eu poderia enfrentar, eu não podia mais esquecer disso (BRUM, 2013).

Este jovem, de apenas 23 anos, ousou insurgir-se contra o poder que grandes corporações detêm sobre o conhecimento acadêmico. Conclamando a todos para lutar contra o que denominava "privatização do conhecimento", baixou 4,8 milhões de artigos acadêmicos da base de dados Journal Storage (JSTOR,) com sede nos Estados Unidos, provavelmente para distribuí-los de forma gratuita. Tal ato resultou em um processo penal pelos crimes de fraude eletrônica e obtenção ilegal de informações, cujo julgamento se daria em abril de 2013. Se condenado, Aaron poderia pegar até 35 anos de prisão e ser obrigado a pagar uma multa de um milhão de dólares. Ele não suportou esperar. Aaron Swartz foi encontrado enforcado em seu apartamento em 11 de janeiro de 2013 (BRUM, 2013; HEFERNAN, 2013).

O caso do jovem norte americano suscita diversas discussões. Pode-se toma-lo pelo viés do software livre e da pirataria, por exemplo. Preferimos, contudo, aqui discutir a questão transversal da propriedade intelectual sobre os resultados da pesquisa acadêmica. No Brasil, grande parte dos achados científicos tem fulcro no financiamento público. Não há sentido, portanto, que os frutos das pesquisas realizadas sob o apoio de agências de fomento de caráter estatal sejam alienados por corporações editoriais.

\section{Por Um Pensamento Local: Sociologia das Ausências e das Emergências}

Para dar visibilidade as experiências sociais alternativas, Santos (2002) realiza a crítica do modelo hegemônico de racionalidade que, seguindo Leibniz, chama razão indolente, propondo como substituto outro modelo, que designa como razão cosmopolita. Para tanto o autor desenvolve três procedimentos sociológicos, a partir da razão cosmopolita: a sociologia das ausências, a sociologia das emergências e o trabalho de tradução. Para tanto, o autor expõe que a forma de compreensão do mundo tem a ver com concepções do tempo. Além disso, o aspecto central da racionalidade hegemônica é o fato de, por um lado, contrair o presente e, por outro, expandir o futuro.

Assim, o autor propõe uma racionalidade cosmopolita cujo fluxo é realizar a trajetória inversa: expandir o presente e contrair o futuro com o objetivo de criar o espaço-tempo necessário para conhecer e valorizar a inesgotável experiência social que está em curso no mundo de hoje. O autor destaca que para expandir o presente, há a necessidade de se fazer uma sociologia das ausências; para contrair o futuro, uma sociologia das emergências.

A sociologia das ausências parte de alguns questionamentos sobre as razões que levaram a um tipo de racionalidade unilateral e excludente que domina o cenário social nos últimos duzentos anos. Para o autor, tornase importante confrontar e superar essa concepção de totalidade e a razão indolente que a sustenta. Esses questionamentos já foram alvos de reflexão por várias vertentes da sociologia crítica, dos estudos sociais e 
culturais da ciência, da crítica feminista, da desconstrução, dos estudos pós-coloniais, etc.

Santos (2002) explica que para superar a hegemonia da razão indolente faz-se necessário por em questão cada uma das lógicas ou modos de produção de ausência que ela sustenta. Para tanto, propõe como alternativa epistemológica, à partida descredibilizadas, as ecologias dos saberes, das temporalidades, dos reconhecimentos, das escalas e das produtividades, definidas como segue (SANTOS, 2002, p. 250).

A ecologia de saberes. A primeira lógica, a lógica da monocultura do saber e do rigor científicos, tem de ser questionada pela identificação de outros saberes e de outros critérios de rigor que operam credivelmente em contextos e práticas sociais declarados não-existentes pela razão indolente.

A ecologia das temporalidades. A segunda lógica, a lógica da monocultura do tempo linear, deve ser confrontada com a ideia de que tempo linear é uma entre muitas concepções do tempo. O domínio do tempo linear não resulta da sua primazia enquanto concepção temporal, mas da primazia da modernidade ocidental que o adotou como seu. Pela modernidade ocidental a partir da secularização da escatologia judaico-cristã, mas nunca eliminou, nem mesmo no Ocidente, outras concepções como o tempo circular, a doutrina do eterno retorno e outras concepções que não se deixam captar adequadamente pela imagem.

A ecologia dos reconhecimentos. A terceira lógica da produção de ausências é a lógica da classificação social. A sociologia das ausências confronta-se com a colonialidade, procurando uma nova articulação entre o princípio da igualdade e o princípio da diferença e abrindo espaço para a possibilidade de diferenças iguais, uma ecologia de diferenças feita de reconhecimentos recíprocos.

A ecologia das escalas. A quarta lógica, a lógica da escala dominante é confrontada pela sociologia das ausências através da recuperação do que no local não é efeito da globalização hegemônica. Ao desglobalizar o local relativamente à globalização hegemônica, a sociologia das ausências explora também a possibilidade de uma globalização contra-hegemônica.

A ecologia da produtividade. A quinta lógica, a lógica produtivista, sobre essa lógica a sociologia das ausências atua na recuperação e a valorização dos sistemas alternativos de produção, das organizações econômicas populares, das cooperativas operárias, das empresas autogeridas, da economia solidária, entre outros, que a ortodoxia produtivista capitalista ocultou ou descredibilizou. Para Santos (2002) este é o domínio mais controverso da sociologia das ausências, uma vez que põe diretamente em questão o paradigma do desenvolvimento e do crescimento econômico infinito que sustenta o capitalismo global. Entretanto, esta lógica nunca dispensou outras formas de produção e apenas as desqualificaram para mantê-las na relação de subalternidade.

A sociologia das emergências, conforme desenvolvida por Santos (2002) consiste em substituir o vazio do futuro segundo o tempo linear por um futuro de possibilidade plural e concreto, simultaneamente utópico e realista. Para o autor a noção que preside à sociologia das emergências é o conceito de ainda-não proposto por Ernst Bloch (1995). Conforme descreve Boaventura Santos, Bloch questiona o fato de a filosofia ocidental ter sido dominada pelos conceitos de Tudo e Nada, nos quais tudo parece estar contido como latência, mas de onde nada novo pode surgir.

Com essas ideias Bloch, salienta Boaventura Santos, introduz dois novos conceitos o Não e o Ainda-Não, sendo aquele a falta de algo e a expressão da vontade de superar essa falta, pois dizer não é dizer sim a algo diferente. O Ainda-Não é uma categoria mais complexa, porque exprime o que existe apenas como tendência, um movimento latente no processo de se manifestar. O Ainda-Não é o modo como o futuro se inscreve no presente e o dilata. Não é um futuro indeterminado nem infinito. É uma possibilidade e uma capacidade concretas que nem existem no vácuo, nem estão completamente determinadas (SANTOS, 2002, p. 255).

Assim, conforme o autor, a sociologia das emergências é a investigação das alternativas que cabem no horizonte das possibilidades concretas. Tem-se com isso, que enquanto a sociologia das ausências amplia o presente, juntando ao real existente o que dele foi subtraído pela razão indolente, a sociologia das emergências amplia o presente, juntando ao real amplo as possibilidades e expectativas futuras que ele comporta. Neste caso, a ampliação do presente implica a contração do futuro, na medida em que o Ainda-não, longe de ser um futuro vazio e infinito, é um futuro concreto, porém incerto.

Desse modo, para o autor, enquanto a sociologia das ausências expande o domínio das experiências sociais disponíveis, a sociologia das emergências expande o domínio das experiências sociais possíveis. É importante destacar, conforme Santos (2002) que as duas sociologias estão estreitamente associadas, visto que quanto mais experiências estiverem disponíveis no mundo mais experiências são possíveis no futuro. Quando maior for a multiplicidade e diversidade das experiências disponíveis e possíveis, maior será a expansão do presente e a contração do futuro. Na sociologia das ausências, essa multiplicação e diversificação ocorrem pela via da 
ecologia dos saberes, dos tempos, das diferenças, das escalas e das produções, ao passo que a sociologia das emergências as revela por vida da amplificação simbólica das pistas ou sinais.

Para Boaventura Santos o rompimento com a razão indolente passa necessariamente pela consideração dos sabres locais o que conduz ao rompimento com a ideia de uma teoria geral para explicar os fenômenos sociais e isso só pode ser realizado pelo trabalho de tradução. Assim, ao se romper com o pensamento único/universal, o trabalho de tradução é um trabalho colonial, uma vez que incide sobre os saberes no plural. Nesse sentido, a tradução é um trabalho intelectual, mas também político, já que subverte as ciências sociais convencionais, marcadas pela razão ocidental indolente, responsável pela redução da realidade às realidades hegemônicas.

\section{Em Oposição as Teorias Totalizadoras: $O$ Trabalho de Tradução e a Transformação Social}

As ciências modernas de inspiração cartesiano-kantiana defendem a construção do conhecimento de forma sistematizada e emoldurada por grandes metanarrativas ou no dizer de Santos (2004) por uma teoria geral. Indo de encontro a essa lógica hegemônica, o autor propõe uma agenda de construção de saberes locais - as ecologias dos saberes - e o trabalho de tradução cuja diversidade de sociabilidade encontra nele um abrigo livre do receio de ser absorvida pelos falsos universalismos e pelas falsas dicotomias das teorias gerais e pela monocultura do saber a ela subjacente.

Um espaço que se afaste das dicotomias em favor da inter-relação, o desenvolvimento epistemológico apoiado na dialogicidade, é também apontado por Islam (2012) quando fala da antropofagia que podemos interpretar como um modo de tradução cultural do Sul global, bem como dos apontamentos de Seremani e Clegg (2015) com a noção do "do terceiro espaço epistemológico" como uma saída para os binarismos ocidentais por meio dos saberes locais, tais como a cultura ubuntu.

$\mathrm{O}$ autor, com base na impossibilidade de se desenvolver uma teoria geral, indaga qual alternativas temos e como resposta propõe o trabalho de tradução. Para Santos (2004), o trabalho de tradução é o procedimento que permite criar inteligibilidade entre as experiências do mundo, tanto as disponíveis como as possíveis, tal como são reveladas pela sociologia das ausências e pela sociologia das emergências, sem solapar com sua autonomia ou multiplicidade.

Encarar o mundo enquanto uma multiplicidade abre espaço para se ver a diversidade de sujeitos políticos e de demandas sociais heterogêneas, o que inopera a tentativa de compartilhamento de um projeto de sociedade comum. Como exemplo da diversidade de posições políticas Santos (2004) cita uma série de movimentos sociais, tais como o movimento feminista, o movimento negro, o movimento indígena, o movimento ecológico que possuem distintas práticas políticas que podem ser até contraditórias e fomentar rivalidades, levando a fragmentação das forças contra hegemônicas.

Essa fragmentação faz parte do mundo social e Santos (2004) propõe o trabalho de tradução entre essas diferenças de forma a articular um projeto de sociedade comum, considerando essa a única maneira de identificar o que divide e o que une os movimentos, de forma a basear as articulações de práticas e de saberes naquilo que os une, e não naquilo que os divide. Essa tarefa implica um vasto exercício de tradução para expandir a inteligibilidade recíproca sem destruir a identidade dos parceiros da tradução.

A finalidade, de acordo com Santos (2004) é criar em todos os movimentos políticos e em todos os discursos ou saberes, uma zona de contato capaz identificar e reforçar o que é comum na diversidade do impulso contra hegemônico. Assim, por meio do trabalho da tradução, a diversidade é celebrada, não como um fator de fragmentação, mas como uma condição de partilha e de solidariedade.

Cabe destacar que o trabalho de tradução incide tanto sobre os saberes como sobre as ações políticas que são, na verdade, inseparáveis. Contudo, para o propósito da tradução importa distinguir entre zonas de contato sobre saberes e zonas de contato sobre ações.

$\mathrm{O}$ trabalho de tradução entre saberes parte da ideia de que todas as culturas são incompletas e que, portanto, podem ser enriquecidas pelo diálogo e pelo confronto com outras culturas. Assim, admitir a relatividade das culturas não implica adotar sem mais o relativismo como posição cultural, mas sim entender o universalismo como uma particularidade ocidental. O trabalho da tradução pressupõe, pelo contrário, a impossibilidade de completude cultural (SANTOS, 2004).

O trabalho de tradução, para frutificar, busca ser o cruzamento de motivações convergentes em diferentes culturas. Para explicar melhor o que isso significa Santos (2004) cita o sociólogo indiano Vishvanathan para formular a seguinte ideia:

"Se pudéssemos imaginar um exercício do trabalho de tradução conduzido entre Vishvanathan e um intelectual europeu, seria possível pensar que a motivação para o diálogo, por parte deste último, fosse formulada assim: "Como posso manter vivo em mim o melhor da cultura ocidental moderna e democrática e, ao 
mesmo tempo, reconhecer o valor do mundo que ela designou autocraticamente como não-civilizado, ignorante, residual, inferior ou improdutivo?" (SANTOS, 2004, p. 9).

Já o segundo tipo de trabalho de tradução é sobre as práticas sociais e os seus agentes. Quando incide sobre as práticas o trabalho de tradução visa criar inteligibilidade recíproca entre formas de organização e entre objetivos de ação e tipos de luta. A especificidade do trabalho de tradução relativo às práticas e seus agentes torna-se mais evidente nas situações em que os saberes que informam diferentes práticas são menos distintos do que as práticas em si mesmas. Isto acontece, sobretudo, quando as práticas ocorrem no interior do mesmo universo cultural como é o caso das formas de organização dos movimentos feminista e operário numa sociedade ocidental. (SANTOS, 2004).

A importância do trabalho de tradução deve-se ao fato de não haver um princípio único de transformação social, tampouco uma determinação a priori das articulações e hierarquias entre as diferentes lutas sociais. Só construindo zonas de contato concretas entre lutas concretas é possível avaliá-las e identificar alianças possíveis entre elas.

Nesse sentido, o trabalho de tradução visa clarificar o que une e o que separa os diferentes movimentos e práticas, de modo a determinar as possibilidades e os limites de articulação entre eles. Dado que não há uma única prática social universal ou sujeito político universal para conferir sentido e direção à história, o trabalho de tradução torna-se decisivo para definir, em cada contexto histórico concreto, quais as constelações de práticas subalternas com maior potencial contra hegemônico.

A tradução visa criar inteligibilidade e articulação num mundo enriquecido pela multiplicidade e diversidade. Muito antes de uma técnica, trata-se de um trabalho dialógico e político. Dotada, igualmente, uma dimensão emocional, pressupõe uma atitude inconformista, por parte do sujeito, em relação aos limites do seu próprio conhecimento e a abertura para aprender com o conhecimento e a prática do outro.

Na visão de Santos (2004) o trabalho de tradução é um exercício de imaginação epistemológica e democrática, visando construir novas e plurais concepções de emancipação social sobre as ruínas da emancipação social do projeto modernista. Não há qualquer garantia de que um mundo melhor seja possível e muito menos de que todos os que lutam por ele o concebam do mesmo modo.

O objetivo do trabalho de tradução é estimular, entre os movimentos sociais, a vontade de criarem em conjunto saberes e práticas suficientemente fortes para fornecer alternativas credíveis à globalização neoliberal. É criar uma zona de contato cosmopolita e a possibilidade de um mundo melhor é imaginada a partir do presente. Uma vez dilatado o campo das experiências, podemos avaliar melhor as alternativas que são possíveis e disponíveis. (SANTOS, 2004).

O trabalho de tradução permite a verificação de que hoje e não amanhã seria possível viver num mundo muito melhor. A possibilidade de um futuro melhor não está num futuro distante, mas na reinvenção do presente, ampliado pela enorme diversidade de saberes e práticas e tornado coerente pelo trabalho de tradução.

\section{Movimentos no Submundo ou as Ausências Produzidas}

Como adiantamos, todos estes fatos foram produzidos como ausentes por uma forma de se fazer ciência que denega a existência a tudo aquilo que não condiz com seus preceitos e pressupostos. A ciência moderna e a alta cultura tornaram-se os únicos critérios de verdade e de estética, declarando como inexistente tudo aquilo que não se lhe coaduna (SANTOS, 2002).

Assim, torna-se importante [...] demonstrar que o que não existe é, na verdade, activamente produzido como não existente, isto é, como uma alternativa não credível ao que existe. O seu objeto empírico é considerável impossível à luz das ciências sociais convencionais, pelo que a sua simples formulação representa já uma ruptura com elas (SANTOS, 2002. p. 11-12).

Tal ideal encontra amparo naquilo que Boaventura de Sousa Santos (2002, p. 12) denomina de Sociologia das Ausências, que pretende "transformar objetos impossíveis em possíveis e com base neles transformar as ausências em presenças". Segundo o autor, produz-se algo como não existente sempre que algo é desqualificado, tornado invisível, ininteligível. No campo dos estudos organizacionais, e para a reflexão dos casos que aqui propomos, observamos que são diversos os processos que operam para a produção de ausências.

A "monocultura do saber" e o "rigor do saber" (SANTOS, 2002. p. 12) são, segundo Boaventura de Sousa Santos, as formas mais poderosas de produção de ausências. Há a produção da não existência quando se ignora "o extraordinário processo de auto-organização", nas palavras de Mike Davis (2012, p. 42), que levou a cabo os movimentos de ocupação em várias partes do mundo no ano de 2011. A reserva do conhecimento apenas para alguns "iluminados" permite que corporações detenham o direito sobre os conhecimentos advindos de pesquisas financiadas com dinheiro público e, permite ainda que aqueles que subvertem esse modelo sejam julgados como 
criminosos.

Ao propor um debate sobre as mudanças proporcionadas pela tecnologia às relações sociais analisadas pela área da Administração, Misoczky e Goulart (2010, p. 215) atentam para o caráter mercantil atribuído ao conhecimento por meio da institucionalização do direito autoral. Segundo as autoras, "o poder, no que tange à disseminação da informação, no campo científico, se concentrou nos editores de revistas científicas e produtores de serviços de indexação e distribuição, majoritariamente privados". Misockzy e Goulart ainda fazem coro com Mueller (2006) ao afirmarem que a situação é mais difícil para países que estão fora dos centros produtores.

Mueller (2006) chama a atenção para o movimento surgido a partir da década de 90 pelo livre acesso ao conhecimento científico. Segundo ela, o advento da publicação eletrônica de periódicos aparecia como a garantia da democratização do acesso ao que era produzido nas universidades. Naquele momento, a tecnologia representava um sonho utópico de socialização do conhecimento. Movimentos como estes exercem pressão sobre a comunidade científica, em meio aos interesses financeiros das editoras, aos interesses das instituições de pesquisas e universidades, e aos interesses pessoais dos pesquisadores, seja dos que estão no topo da hierarquia, seja dos que desejam ascender nesta estrutura.

A noção de organização hegemonicamente difundida na academia pressupõe, entre outros pontos, a ideia de uma ação racional orientada a fins (KALBERG, 1980), com foco em objetivos coletivos, mensuráveis e claramente definidos (PARKER, 2002). Contudo, como escreve Mike Davis (2011, p.40), “o movimento Occupy the World ainda procura seus óculos mágicos (programa, demandas, estratégia e assim por diante)" e assim, continuam tais movimentos, ausentes frente aos estudos organizacionais. Mas Davis logo alerta que basta ameaçar aspectos fundamentais da vida dos cidadãos, como suas moradias ou empregos, "para que algo novo e de grandes proporções comece a se dirigir de modo lento e cambaleante ao Goldman Sachs” (DAVIS, 2011. p. 40).

Ignorar a organização presente em movimentos como estes é descredibilizar o movimento, nas palavras de Boaventura de Sousa Santos (2002) ou descridibilizar o próprio povo, como diria Paulo Freire (2011. p. 173):

[...] evitar o diálogo com o povo] em nome da necessidade de "organizá-lo", de fortalecer o poder revolucionário, de assegurar uma frente coesa é, no fundo, temer a liberdade. É temer o próprio povo ou não crer nele. Mas, ao se descrer do povo, ao temê-lo, a revolução perde sua razão de ser.

Outra forma de construção das ausências é a lógica da classificação social que naturaliza a distribuição dos indivíduos por categorias hierarquizadas (SANTOS, 2002). Assim, qualquer insurgência contra esta ordem preestabelecida deve ser descredibilizada. "De acordo com esta lógica, a não existência é produzia sob a forma de inferioridade insuperável porque natural. Quem é inferior, porque é insuperavelmente inferior, não pode ser uma alternativa credível a quem é superior" (SANTOS, 2002. p. 13).

A lógica da classificação social traveste-se de paternalismo (FREIRE, 2011), apresenta-se das mais variadas formas, é lobo em pele de cordeiro. O antidialógico dominador manipula o oprimido no sentido de promover uma certa organização. Tal organização, tal ordenação imposta pelo conquistador, não é outra senão aquela que mantenha o status quo. Tal organização se sustenta no "modelo que a burguesia faz de si mesma às massas como possibilidade de sua ascensão" (FREIRE, 2011. p. 198), mas cujo fim é "conseguir um tipo inautêntico de 'organização', com que se evite o seu contrário, que é a verdadeira organização das massas populares emersas e emergindo" (Idem).

A transformação do outro em ausente, em não-existente, se dá, também, por meio da lógica produtivista (SANTOS, 2002). "Nos termos desta lógica, o crescimento económico é um objetivo racional inquestionável e, como tal, é inquestionável o critério e produtividade que mais bem serve a este objetivo (SANTOS, 2002. p. 14). Nem a crise do modelo de produção fordista foi capaz de fazer com que os mais diferentes modelos e concepções de organização prescindissem de estreitar o seu foco em torno das organizações produtivas (PAES DE PAULA, 2002).

A preocupação dos estudiosos é estacionária na acumulação de capital e na garantia da mediação estatal dos interesses públicos e privados por parte do Estado. Não há espaço para aquele que não produz. A dinamicidade da transformação das teorias administrativas centra-se na sua capacidade de manter o modelo de acumulação capitalista vigente. Neste mesmo sentido, Paes de Paula (2002. p.129), a partir de reflexões sobre a obra de Mauricio Tragtenberg afirma que mesmo as mais novas teorias administrativas "são tributárias das antigas escolas de administração e do modelo burocrático de organização, uma vez que continuam propagando métodos funcionalistas, estratégias redutoras de conflitos e formas de dominação”.

Os instrumentos tecnológicos, as novas práticas de gestão e os modismos gerenciais estão a serviço da prosperidade da organização produtiva. Mecanismos de controle e novas tecnologias são associados em prol de vigiar trabalhadores (CLEGG, 1992. SILVA, 2003. SILVA; ALCADIPANI, 2001). Modismos e inovações 
surgem a cada dia em nome do aumento da produção. Nesta esteira vimos o downsizing e a reengenharia (WOOD JR.; CALDAS, 1995), a qualidade total (WOOD JR., URDAN, 1994) e a preocupação com a liderança como forma de controle (PRESTES MOTTA; VASCONCELOS; WOOD JR., 1995; SILVA, 2003).

Esse punho de ferro em luva de pelica (nós tomamos emprestada a expressão de Jermier, 1998) em que se transformou o controle organizacional nas organizações atuais opera e necessita de uma transformação no papel da liderança. A liderança passa a representar um "retorno ao carisma", personalizando as estruturas de legitimação (Courpasson, 2000a) e construindo para e com os atores organizacionais uma visão de mundo que justifica as ações gerenciais, principalmente, pelas ameaças externas. A principal arma da liderança frente a esta nova configuração do controle organizacional passa a ser o "discurso" que informa, transmite os valores, fornece as interpretações e os scripts (Grey \& Garsten, 2001) da organização. (SILVA, 2003. p. 800).

O resultado disso, o reflexo mais límpido desta orientação produtivista nos estudos organizacionais é a ausência de referência às formas de organização da sociedade voltadas à ação transformadora (MISOCZKY, 2010, PAULA, 2012), à libertação (MISOCZKY, 2010; FARIA, 2007; PAULA, 2013); ao cooperativismo (BOEIRA et al, 2012) e a autogestão (MOTTA, 1981). Nada se fala, em nosso campo, dos jovens indignados dos movimentos anticapitalistas europeus, dos shabab (jovens) insurgentes no mundo árabe, do movimento estudantil chileno e da ocupação de Wall Street (CARNEIRO, 2011).

Todos estes movimentos contam com formas próprias de organização e lançam mão de ferramentas tecnológicas a favor da libertação. É inegável o papel de sites de redes sociais como o Facebook e o Twitter na organização dessas manifestações, e assim, "o Occupy Wall Street, o Movimento dos Indignados e movimento Geração à Rasca são exemplos candentes da verdadeira globalização 'dos de baixo', que hoje se contrapõe à globalização dos 'de cima"' (ALVES, 2011. SANCHEZ, 2011).

\section{Os Seres do Subterrâneo Vem à Tona ou o Tempo das Emergências}

É, pois, chegado o momento de se falar das possibilidades. Boaventura de Sousa Santos (2002. p. 24) define a "sociologia das emergências" como a "investigação das alternativas que cabem no horizonte das possibilidades concretas". Segundo ele, "a possibilidade é o movimento do mundo" (Ibidem. p. 24). É assim, com Josefina, a Cantora, do último conto de Kafka. Nada de mágico há na cantora-camundongo que não faz outra coisa senão assobiar. Todos os camundongos ali eram capazes de assobiar. Isso, todavia, encontrava-se oculto no esquecimento e o silêncio imperava.

Tal movimento, contudo, não se dá em regime de linearidade. O tempo não é fluxo linear. O que nos cabe, ao praticarmos a sociologia das emergências, é a construção de um futuro. Esta obra não se empreende sobre um vazio, mas constrói-se a partir de possibilidades que são, ao mesmo tempo, plurais e concretas, utópicas e realistas. Vençamos, assim, a "lógica do tempo linear", própria da sociologia das ausências (SANTOS, 2002), pois, como aponta Walter Benjamin o tempo em que se dá a libertação é um tempo que compreende os saltos, o surgimento (Ur-sprung), a interrupção, a descontinuidade. "O continuum da história é o dos opressores. Enquanto a representação do continuum iguala tudo ao nível do chão, a representação do descontínuo é o fundamento da autêntica tradição" (BENJAMIN, 1974. p. 236 apud GAGNEBIN, 2007. p. 99). Neste sentido, Jeanne Marie Gagnebin (2007. p. 99), acrescenta que "acolher o descontínuo da história, proceder à interrupção desse tempo cronológico sem asperezas, também é renunciar ao desenvolvimento feliz de uma sintaxe lisa sem fraturas".

Santos (2002) explica que um conceito subjacente ao da sociologia das emergências é aquele cunhado por Ernst Bloch (1995), de Ainda-Não (Noch Nicht). Tal proposição advoga que a filosofia ocidental é estática e pauta-se pelas ideias de Tudo (Alles) e Nada (Nichts), pretendendo, assim, abarcar todas as possibilidades, guardando as latências e não vislumbrando a possibilidade do novo. $\mathrm{O}$ acréscimo proposto por Bloch dos conceitos de Não (Nicht), que conduz à ideia de falta e de superação desta falta, já que uma negação pressupõe uma afirmação contrária e correspondente, e, Ainda-Não (Nocht Nicht), aquilo que permanece no campo da tendência, que não é manifesto nem negado, contempla a capacidade (potência) e a possibilidade (potencialidade), é o que permite a extensão do futuro, em nome de outras possibilidades. Nas palavras de Santos (2002, p. 24) "o Ainda-Não, longe de ser um futuro vazio e infinito, é um futuro concreto, sempre incerto e sempre em perigo" e acrescenta "é impossível a esperança sem a eventualidade do caixão".

A redução do tempo presente entre aquilo que já foi e o que ainda não é (SANTOS, 2002) expressa uma arrogância própria de quem determina o ritmo do tempo e a extensão da contemporaneidade. Neste sentido, Derrida (1967) propõe a ideia de differánce. Ao contrário da differénce, o termo cunhado por ele não resolve, não decide, não exclui. A não-decisão adia o futuro, propaga-o a um momento outro. Não se esgotam as possibilidades. Somente assim, pela potência de não-ser, dá-se o ato em sua perfeição. A potência de ser esgotase em si própria, enquanto a potência de não-ser compreende todas as possibilidades. Somente pode não-ser, 
aquele que poderia ser. (AGAMBEM, 1993).

Paulo Freire (2011) defende a dinamicidade permanente da revolução. Homens em constante processo de libertação, não havendo, portanto um antes e um depois, divididos e sinalizados pela tomada do poder. Neste sentido, prossegue, não há a libertação individual ou a libertação do outro ou a libertação pelo outro. O que há são homens que se libertam em comunhão. Ele refuta qualquer rótulo de ingênuo ou de idealista, eis que não existe nada mais real que os homens no mundo e os homens com os homens, oprimindo e sendo oprimidos.

Salvoj Žižek (2012) afirma algo semelhante em relação aos insurgentes dos movimentos de ocupação de 2011:

Os manifestantes são descartados como sonhadores, mas os verdadeiros sonhadores são os que pensam que as coisas podem continuar indefinidamente como estão, com apenas algumas mudanças cosméticas. Eles não são sonhadores, são o despertar de um sonho que está se transformando em pesadelo. Não estão destruindo nada, estão reagindo como ao modo como o sistema gradualmente destrói a si próprio (ŽIŽEK, 2012. p. 17).

Os movimentos insurgentes são frequentemente criticados pela falta de um projeto em substituição àquele contra qual se opõe, contudo, mobilizamos, mais uma vez, das palavras de Žižek (2012. p. 18), segundo quem,

devemos resistir precisamente a uma tradução assim apressada da energia das manifestações para um conjunto de demandas pragmáticas 'concretas'. Sim, os protestos realmente criaram um vazio - um vazio no ampo da ideologia hegemônica - e será necessário algum tempo para preenchê-lo de maneira apropriada posto que se trata de um vazio que carrega consigo um embrião, uma abertura para o verdadeiro Novo.

Mitiga-se assim, a lógica da monocultura do saber e do rigor do saber (SANTOS, 2002). "Os intelectuais definitivamente não estão na posição de Sujeito Suposto Saber: não podem operacionalizar tais demandas para traduzi-las em propostas para medidas realistas precisas e detalhadas" (ŽIŽEK, 2012. p. 24). Enxergamos aqui a vitória do Ainda-Não, próprio da sociologia das emergências, possibilidades, tendências, vislumbres de novos caminhos para a libertação. São estas ações as que desaceleram o presente, fazendo ser mais que um simples ponto entre o passado e o futuro (SANTOS, 2002).

A sociologia das emergências expande o domínio das experiências sociais possíveis (SANTOS, 2002). Já não nos é possível precisar, sempre, as disputas presentes nas lutas de resistência. O movimento em defesa de Bradley Manning pedia por um julgamento ao ex-militar. Mas pede também pela abertura de informações do exército americano, pede pela liberdade para que seus membros falem. Falem sobre o que acontece nos campos de guerra, falem sobre como são tratados, falem sobre como eles próprios são. O que se passa nos fronts ainda é segredo de estado. Militares gays ainda vivem sob o regime Don't Ask, Don't Tell.

Mohamed Bouazizi procurava resolver um problema pessoal sobre a sua licença para vender frutas na rua. Tornou-se, todavia, pivô de uma discussão mundial que, apenas no seu princípio, teve como centro a praça Tahrir. Logo a onda colérica de insatisfação espalhava-se pelo globo e lutavam, em sincronia, jovens na Espanha e em Portugal, estudantes no Chile, trabalhadores na Grécia, pessoas em Wall Street.

Entre milhares de pessoas, encontram-se, lado a lado, por exemplo, jovens anticapitalistas e enfermeiras em defesa do sistema de saúde. Há cartazes de protesto contra o racismo, o presidente Obama, os republicanos, os democratas, as guerras no Iraque e no Afeganistão (ALVES, 2012. p. 32).

Subverteu-se, neste processo o uso das tecnologias de comunicação e informação. Se estavam elas a serviço da acumulação de capital e da dominação, agora conectam indignados nos mais longínquos espaços. A área de intervenção e mobilização foi ampliada pelo uso do Facebook e do Twitter. "A luta contra o capital global que desterritorializa é a luta pela territorialização ampliada, difusa e descentrada" (ALVES, 2012. p. 33).

Por estas características, fluidas, etéreas, virtuais, estes movimentos não têm um líder. (ALVES, 2012). Não há espaço, aqui, para uma liderança que pretenda manejar a sua comunidade. A única possibilidade que se vislumbra é a de uma liderança que emerja como tal, constituindo-se em contradição com as elites dominadoras. A ação dialógica e libertadora apenas pode comportar uma liderança revolucionária (FREIRE, 2011).

$\mathrm{Na}$ ação antidialógica, a manipulação, a conquista e a dominação exercem os seus papéis a serviço de uma elite constituída. As proposições da ação dialógica antagonizam com estes princípios por meio da organização das massas populares. A busca pela libertação pressupõe uma organização que está para além da unidade, constituindo-se em "um desdobramento natural desta unidade das massas populares" (FREIRE, 2011. p. 240). As formas de organização para a resistência representam, para Mike Davis (2012) o triunfo da organização dialógica.

Josefina, a única que consegue cantar, enquanto todos poderiam fazê-lo, conduz à reunião todo o seu povo. Josefina catalisa em si, na sua singularidade, toda a universalidade daquele povo. Ela é um, por meio do qual todos se enxergam. Por isso, Josefina não é vista como mestre ou tratada como gênio. É apenas mais um dentre 
os camundongos. Trata-se aqui de uma comunidade genuinamente igualitária, que Kafka somente poderia imaginar habitada por animais. A importância da cantora, contudo, não se dá ao agir, pelo seu canto, mas ao permitir que todos se reúnam em silêncio. $\mathrm{O}$ foco, aqui, não está na ação, ao cantar, mas na potência, ao silenciar.

A liderança revolucionária não organiza as massas, não lhes diz o que fazer. A liderança revolucionária se organiza com as massas populares. A liderança revolucionária é tão impedida de dizer palavra quanto as massas populares. No processo de organização, não reifica, não conduz, não maneja, "instaura o aprendizado da pronúncia do mundo, aprendizado verdadeiro, por isto, dialógico" (FREIRE, 2011. p. 242).

A liderança revolucionária proposta por Paulo Freire é, por assim dizer, praticante da sociologia das emergências, de Boaventura de Sousa Santos, uma vez que abriga um ato de anúncio. É por meio da organização dialógica que se poderão fazer presentes aqueles produzidos como ausentes. É por meio da luta pela libertação, não para, mas com os oprimidos que virão à tona os submersos, os descredibilizados, os inexistentes.

A superação do mito de que a ordem opressora é uma ordem de liberdade, do "mito do heroísmo das classes opressoras como mantenedoras da ordem que encarna a 'civilização ocidental e cristã', que elas defendem da 'barbárie materialista' (FREIRE, 2011. p. 188) apenas terá vez por meio de experiências sociais alternativas contidas no Anda-Não (SANTOS, 2002). Esse é o tempo da não-decisão (DERRIDA, 1967), um tempo que supera a pressão da lógica do tempo cronológico (SANTOS, 2002) e que não cabe na organização moderna (PARKER, 2002).

Os movimentos que emergem das massas, obedecem ao tempo da natureza das massas. É assim, também, na história da rata cantora, em que o prazer de ouvi-la assobiar ornamentava os momentos de decisão, como que mostrando que, apesar da pressão mundana, deveriam, eles, preservarem algo da sua natureza.

Esse assobio, que se eleva onde o silêncio se impõe a todos os outros, chega ao indivíduo quase como uma mensagem do povo; seu assobio fino, em meio às decisões difíceis, é quase como a existência miserável do nosso povo em meio ao tumulto do mundo hostil. Josefina se afirma - esse nada de voz, esse nada de desempenho se afirma e abre caminho até nós: faz bem pensar nisso (KAFKA, 1998. p. 47).

A superação dos mitos antidialógicos da dominação (FREIRE, 2011) será concomitante com a transposição da monocultura do saber e do rigor do saber, da lógica da classificação social, da lógica produtivista (SANTOS, 2002). A organização para a resistência e a libertação, a organização dialógica, somente será visível, somente estará presente, somente emergirá, se formos capazes de superar as ideias, inclusive as da ciência, que asseguram não haver alternativa.

\section{Referências}

ADORNO, T. W. O Ensaio como forma. In: ADORNO, T. W. Notas de Literatura I. Tradução de Jorge de Almeida. São Paulo: Ed. 34, 2003. p. 15-45.

AGAMBEN, G. A comunidade que vem. Lisboa: Presença, 1993.

AL-ARAB, M.; HUNT, N. How a fruit seller caused revolution in Tunisia. CNN. [S.1], 16 jan. 2011. Disponível em: <http://edition.cnn.com/2011/WORLD/africa/01/16/tunisia.fruit.seller.bouazizi/index.html>. Acesso em: 05 fev. 2013.

ALVES, G. Ocupar Wall Street... e depois? In: HARVEY, David et al. Occupy: movimentos de protesto que tomaram as ruas. São Paulo: Boitempo: Carta Maior, 2012. p. 27-38.

BARRENTO, J. Limiares: Sobre Walter Benjamin. Florianópolis: EdUFSC, 2013.

BOEIRA, S. L.; SIMON, V. P.; LEAL, J. V. N.; REZENDE, G. M. Reflexão sobre aspectos teóricos e epistemológicos da produção nacional relativa ao cooperativismo. In: II Colóquio Internacional de Epistemologia e Sociologia da Ciência da Administração, 2012, Florianópolis. II Colóquio Internacional de Epistemologia e Sociologia da Ciência da Administração, 2012.

BÖHM, S. Repositioning Organization Theory: Impossibilities and Strategies. Basingstoke: Palgrave, 2006.

BRUM, E. Perdão, Aaron Swartz. Época, São Paulo, n., p.1-2, 21 jan. 2013. Disponível em: $<$ http://revistaepoca.globo.com/Sociedade/eliane-brum/noticia/2013/01/perdao-aaron-swartz.html $>$. Acesso em: 25 jan. 2013.

BYRNE, E. Death of a street seller that set off an uprising. Financial Times, [S.1]. 16 jan. 2011. Disponível em: $<$ http://www.ft.com/intl/cms/s/0/6ed028a2-21a2-11e0-9e3b-00144feab49a.html\#axzz2KXR7hNUu>. Acesso em: 05 fev. 2013.

CARNEIRO, H. S. Apresentação - Rebeliões e ocupações de 2011. In: HARVEY, David et 
al. Occupy: movimentos de protesto que tomaram as ruas. São Paulo: Boitempo: Carta Maior, 2012. p. 27-38.

CHANLAT, J. Ciências Sociais e Management: reconciliando o econômico e o social. São Paulo: Atlas, 1999.

CLEGG, S. As organizações modernas. Lisboa: Celta Editora/Oeiras, 1998.

CLEGG, S. Tecnologia, Instrumentalidade e Poder nas Organizações.Rae, São Paulo, v. 32, n. 5, p.68-95, nov. 1992. Tradução de Geni Garcia Golschmidt. Disponível em: $<$ http://rae.fgv.br/sites/rae.fgv.br/files/artigos/10.1590_S0034-75901992000500008.pdf>. Acesso em: 05 fev. 2013.

DAVIS, M. Chega de chiclete. In: HARVEY, David et al. Occupy: movimentos de protesto que tomaram as ruas. São Paulo: Boitempo: Carta Maior, 2012. p. 27-38.

DERRIDA, J. A escritura e a diferença. São Paulo: Perspectiva, 1967.

DERRIDA, J. Margens da Filosofia. São Paulo: Papirus, 1991.DUSSEL, Enrique. Ética de la liberación. (Hacia el "punto de partida" como ejercicio de la "razón ética originaria"). In: DUSSEL, Enrique. APPEL, Karl-Otto. Ética del discurso. Ética de la liberación. Madrid: Trotta, 2004.

FARIA, J. H. (org). Análise critica das teorias e práticas organizacionais. São Paulo: Atlas, 2007.

FREIRE, P. A pedagogia do oprimido. 50. ed. rev.e atual. São Paulo: Paz e Terra, 2011.

GAGNEBIN, J. M. História e narração em Walter Benjamin. 2. ed. São Paulo: Perspectiva, 2007.

GREENWALD, G. The inhumane conditions of Bradley Manning's detention. Salon, [S.1]. 15 dez. 2010. Disponível em: <http://www.salon.com/2010/12/15/manning_3/>. Acesso em: 05 fev. 2013.

HEFFERNAN, V. Aaron Swartz, 1986-2013: a computer hacker who is now a political martyr. Yahoo! News, [New York]. 12 jan. 2013. Disponível em: <http://news.yahoo.com/what-we-learned-from-aaron-swartzs-suicide-004332081.html>. Acesso em: 07 fev. 2013.

ISLAM, G. Can the subaltern eat? Anthropophagic culture as a Brazilian lens on post-colonial theory. Organization, 19(2), 159-180, 2012.

KAFKA, F. Josefina, a Cantora ou O Povo dos Camundongos. In: KAFKA, Franz. Um artista da fome / A construção. São Paulo: Companhia das Letras, 1998. p. 37-60.

KALBERG, S. Max Weber's Types of Racionality: Cornestones for the Analysis of Racionalization Processes in History. American Journal Of Sociology, Chicago, v. 85, n. 5, p.1145-1179, 1980.

LEVS, J. Self-immolation reports spread through north Africa. CNN, [S.1], p. 1-2. 17 jan. 2011. Disponível em: $<$ http://edition.cnn.com/2011/WORLD/africa/01/17/tunisia.self.immolation/>. Acesso em: 05 fev. 2013.

MISOCZKY, M. C. A.; FLORES, R. K.; SILVA, S. M. G. Estudos organizacionais e movimentos sociais: o que sabemos? Para onde vamos? Cadernos Ebape.br, Rio de Janeiro, v. 6, n. 3, p.1-14, set. 2008. Disponível em: $<$ http://www.lume.ufrgs.br/bitstream/handle/10183/21313/000684974.pdf?sequence=1>. Acesso em: 05 fev. 2013.

MIZOCZKI, M. Das práticas não-gerenciais de organizar à organização para a práxis da libertação. In.: MIZOCZKI, M., FLORES, R., MORAES, J. (org). Organização e práxis libertadora. Porto Alegre: Dacasa Editora, 2010.

MIZOCZKI, M.; GOULART, Sueli. A quem pertence o conhecimento que produzimos? In.: MIZOCZKI, M., FLORES, R., MORAES, J. (org). Organização e práxis libertadora. Porto Alegre: Dacasa Editora, 2010.

MOTTA, F. C. P. Burocracia e autogestão: a proposta de Proudhon. São Paulo: Brasiliense, 1981.

MOTTA, Fernando P; VASCONCELOS, Isabela; WOOD JUNIOR, Thomaz. O novo sentido da liderança: controle social nas organizações. In: WOOD JUNIOR, Thomaz. Mudança organizacional: aprofundando temas atuais em administração de empresas. 2. ed. São Paulo: Atlas, 2000. p. 119-151.

MUELLER, S. P. M. A comunicação científica e o movimento de acesso livre ao conhecimento. Ci. Inf., Brasília, v. 35, n. 2, Aug. 2006.Disponível em <http://www.scielo.br/scielo.php? script=sci_arttext\&pid=S0100-19652006000200004\&lng=en\&nrm=iso>. Acessado em 02 Fev. 2013.

PARKER, M. Against Management: Organization in the Age of Managerialism. Cambridge: Polity, 2002.

PAES DE PAULA, A. P. Tragtenberg revisitado: as inexoráveis harmonias administrativas e as burocracias flexíveis. Revista de Administração Pública, v. 36, n. 1, 2002.

PAULA, A. P. P. Teoria Crítica nas organizações. São Paulo: Thomson Learning, 2008. PAULA, A. P. P. Estilhaços do Real: o ensino da administração em uma perspective benjaminiano. Curitiba: Juruá, 2012.

PAULA, A.P.P. Abordagem Freudo-Frankfurtiana, Pesquisa-Ação e Socioanálise_uma proposta alternativa para 
os Estudos Organizacionais. Cad. EBAPE.BR, v. 11, n. 4, artigo 2, Rio de Janeiro, Dez. 2013.

SANCHEZ, A. Um desempregado, um bolseiro e uma estagiária inventaram o Protesto da Geração à Rasca. Publico, Lisboa. 26 fev. 2012. Disponível em: $<$ http://www.publico.pt/sociedade/noticia/umdesempregado-um-bolseiro-e-uma-estagiaria-inventaram-o-protesto-da-geracao-a-rasca-1482270>. Acesso em: 07 fev. 2013.

SANTOS, B. Para uma sociologia das ausências e uma sociologia das emergências. Revista Crítica de Ciências Sociais, v.63, p. 237-280, 2002.

. O futuro do Fórum Mundial Social: o trabalho de tradução. Revista OSAL, n. 1 vol. 15, 2004.

SEREMANI, T. W.; CLEGG, S. Postcolonialism, Organization, and Management Theory: The Role of "Epistemological Third Spaces". Journal of Management Inquiry, 2015.

SERVA, M; DIAS, T; Alperstedt, G. O paradigma da complexidade e a teoria das organizações: uma reflexão epistemológica. RAE (Impresso), v. 50, p. 276-287, 2010.

SILVA, R. C.; ALCADIPANI, R. As Transformações do Controle na Siderúrgica Riograndense - uma análise foucaultiana. O\&S. Organizações \& Sociedade, Salvador-BA, v. 11, n.29, p. 81-96, 2004.

SILVA, R. C. Controle organizacional, cultura e liderança: evolução, transformações e perspectivas. RAP, Rio de Janeiro, v. 37, n. 4, p.797-816, jul. 2003.

SILVA, R. C. Controle organizacional, cultura e liderança; evolução, transformações e perspectivas. Revista de Administração Pública, v. 37, n. 4, 2003.

THE ECONOMIST. Commons man. The Economist, [s.1], p. 1-2. 13 jan. 2013. Disponível em: $<$ http://www.economist.com/blogs/babbage/2013/01/remembering-aaron-swartz>. Acesso em: 05 fev. 2013.

TUTU, D.; CORRIGAN-MAGUIRE, M.; ESQUIVEL, A. P. Bradley Manning deserves Americans' support for military whistleblowing: Thanks to WikiLeaks, US citizens are better informed about wars prosecuted in their name. We owe Manning honour, not jail time. The Guardian, London, 16 nov. 2012. p. 1-2. Disponível em: $<$ http://www.guardian.co.uk/commentisfree/2012/nov/16/bradley-manning-americans-support $>$. Acesso em: 05 fev. 2013.

WOOD JR, T.; CALDAS, M. P. Quem tem medo de Eletrochoque? Identidade, Terapias Convulsivas e Mudança Organizacional. RAE. Revista de Administração de Empresas, São Paulo, v. 35, p. 13-21, 1995.

WOOD JUNIOR, T.; URDAN, F. T. Gerenciamento da Qualidade Total: uma Revisão Crítica. Rae, São Paulo, v. 34, n. 6, p.46-59, nov. 1994. Disponível em: <http://rae.fgv.br/rae/vol34-num6-1994/gerenciamento-qualidadetotal-revisao-critica>. Acesso em: 07 fev. 2013.

ZANATTA, R. A. E. Aaron Swartz, guerrilheiro da internet livre. Fórum, Porto Alegre, n., p.1-2, 17 jan. 2013. Mensal. Disponível em: <http://revistaforum.com.br/blog/2013/01/aaron-swartz-guerrilheiro-da-internet-livre/>. Acesso em: 05 fev. 2013.

ŽIŽEK, S. O violento silêncio de um novo começo. In: HARVEY, David et al. Occupy: movimentos de protesto que tomaram as ruas. São Paulo: Boitempo: Carta Maior, 2012. Cap. 2, p. 15-26. 